\title{
Pattern of Bacteria Causing Urinary Tract Infections and Their Antibiotic Susceptibility Profile at Chittagong Medical College Hospital
}

\author{
MA Mazed, Anwar Hussain, Nasima Akter, Tipu Sultan, Arup Kanti Dewanje \\ Department of Microbiology, Chittagong Medical College, Chittagong
}

\begin{abstract}
Urinary tract infection (UTI) is the most common nosocomial infection among hospitalized patients. Area-specific monitoring studies aimed to gain knowledge about the type of pathogens responsible for UTIs and resistance pattern of the causative agents may help clinicians to choose correct treatment regimen. So, the present study was aimed to investigate the antibiotic resistance of urinary pathogens isolated at Chittagong Medical College Hospital (CMCH) during January to June, 2007. Out of 360 clinical samples of urine collected, $175(\mathbf{4 8 . 6 1 \% )}$ showed significant bacterial growth. The most common pathogens isolated were Escherichia coli $(66,37.71 \%)$, Klebsiella species (60, 34.29\%), Proteus species $(17,9.71 \%)$ and Pseudomonas species $(16,9.14 \%)$. Members of the Enterobacteriaceae were 80\%$100 \%$ sensitive to Imipenem while they were found variably sensitive to other commonly used antibiotics. Pseudomonas species were $\mathbf{1 0 0} \%$ sensitive to Imipenem, $\mathbf{7 5 \%}$ to Amikacin, and $\mathbf{5 0 \%}$ to Ceftazidime. Staphylococcus aureus was found $\mathbf{1 0 0 \%}$ sensitive to Vancomycin, $\mathbf{8 0 \%}$ to Gentamicin and Amikacin each, and $55 \%$ to Oxacillin. Enterococcus species were $80 \%$ sensitive to Imipenem, $60 \%$ to Ciprofloxacin, $50 \%$ to Vancomycin and Amikacin each. The clinicians should use Imipenem selectively in cases of un-responsiveness to commonly used antibiotics.
\end{abstract}

Kewords: Urinary tract infection, Nosocomial infection, Escherichia coli, Klebsiella species

\section{Introduction}

Urinary tract infection (UTI) is one of the most important causes of morbidity in the general population, and is the second most common cause of morbidity among hospital vtsitors. Moreover, UTI was found as the most common cause of nosocomial infection among hospitalized patients. ${ }^{1}$ With advancing age, the incidence of UTI increases in men due to prostate enlargement and neurogenic bladder. ${ }^{2}$ Recurrent UTI are common and can lead to irreversible damage to the kidneys, resulting in renal hypertension and renal failure in severe cases. ${ }^{3}$ In the community, women are more prone to develop UTI. It has been observed that about $20 \%$ of the

Correspondence:

Dr. MA Mazed

Assistant Professor

Department of Microbiology

Chittagong Medical College, Chittagong women experienced a single episode of UTI during their lifetime, and $3 \%$ of women had more than one episode of UTI per year. ${ }^{4}$ Pregnancy also makes the women more susceptible to the infection. ${ }^{5}$ Catheter-associated UTI is a trenchant problem with about $10 \%$ of the patients developing bacteriuria. ${ }^{6}$

It is universally accepted that UTI can only be ascertained on the basis of microscopy and microbial culture of urine. The dip stick method used in many centres serves only as a screening method but culture is needed for final diagnosis. ${ }^{7}$ In almost all cases of nosocomial UTI, there is a need to start treatment before the final microbiological results are available. Area-specific monitoring studies aimed to gain knowledge about the types of pathoges responsible for UTIs and their resistance pattern may help the clinician to choose the correct empirical treatment. 
Studies from India, Bangladesh and Nepal have reported an increased resistance of the urinary pathogens to commonly used antibiotics. ${ }^{8-10}$ Any information from similar studies was not available in the tertiary care hospital at Chittagong. Hence, this study was undertaken to find out the frequency and antibiotic susceptibility pattern of urinary pathogens isolated from urine samples of suspected cases of UTIs at Chittagong Medical College Hospital (CMCH).

\section{Methods}

This was a cross-sectional study conducted at the department of Microbiology, Chittagong Medical College (CMC). The samples of urine were obtained from patients of various clinical wards and outpatients departments of the CMC Hospital, during the period of January, 2007 to June, 2007.

The patients having suggestive symptoms and /or signs were suspected as cases of UTI. Urine samples were collected by standard mid-stream clean-catch method from all the cases. Urine samples were also collected from catheterized patients. The samples were inoculated on the Blood agar and MacConkey agar media by calibrated wire loop and incubated at $37^{\circ} \mathrm{C}$ overnight. The plates were observed for bacterial growth. The isolates were identified by observing colony morphology, Gram-stain characteristics and relevant biochemical tests. ${ }^{11}$ Culture results were interpreted according to the standard criteria and a growth of $\geq 10^{5}$ colony forming units $/ \mathrm{ml}$ was considered as significant bacteriuria. ${ }^{12}$ Antibiotic susceptibility test was carried out by the Kirby Bauer technique ${ }^{13}$ and interpretations were made for each bacterial isolate following interpretative criteria recommended by the National Committee for Clinical Laboratory Standards (NCCLS). ${ }^{14}$

Appropriate quality control strains were used to validate the results of the antimicrobial disk. The following were the quality control strains used: Pseudomonas species NCTC10662, Staphylococcus aureus NCTC-6571, Escherichia coli NCTC-10418.

\section{Results}

Out of 360 samples of urine, 175 (48.61\%) showed significant growth of uropathogens. Considering age distribution of the culture-positive cases, $16(9.14 \%)$ were children aged 10 years or less, and $40(22.86 \%)$ were aged 60 years and above. In all age groups, except those aged 0-10 years, females were more frequently affected than males. (Table I)
Table I: Age and sex distribution of the culture positive urine samples

\begin{tabular}{llll}
\hline $\begin{array}{l}\text { Age groups } \\
\text { in years }\end{array}$ & \multicolumn{2}{c}{ No of samples from- } \\
Male & Female & Total \\
\hline $0-10$ & 10 & 06 & $16(9.14 \%)$ \\
$11-20$ & 14 & 17 & $31(17.71 \%)$ \\
$21-40$ & 12 & 22 & $34(19.43 \%)$ \\
$41-60$ & 14 & 40 & $54(30.86 \%)$ \\
Above 60 & 19 & 21 & $40(22.86 \%)$ \\
Total & 69 & 106 & $175(100.0 \%)$ \\
\hline
\end{tabular}

The commonest organisms isolated were Escherichia coli $(66,37.71 \%)$ and Klebsiella species $(60,34.29 \%)$ followed by Proteus species $(17,9.71 \%)$, Pseudomonas species (16, $9.14 \%)$ and others including Coagulase-negative Staphylococcus $(2.86 \%)$. (Table II)

Table II: Distribution of bacterial isolates among 175 culture positive cases

\begin{tabular}{lllr}
\hline $\begin{array}{l}\text { S1. } \\
\text { no }\end{array}$ & Name of bacteria & $\begin{array}{l}\text { No. of } \\
\text { isolates }\end{array}$ & Percentage \\
\hline 1 & E. coli & 66 & 37.71 \\
2 & Klebsiella spp & 60 & 34.29 \\
3 & Proteus spp & 17 & 9.71 \\
4 & Pseudomonas spp & 16 & 9.14 \\
5 & Staphylococcus aureus & 06 & 3.43 \\
6 & Enterococci & 05 & 2.86 \\
7 & Coagulase-negative & 05 & 2.86 \\
& Staphylococcus & & 100.00 \\
\hline
\end{tabular}

E. coli and Klebsiella were found highly sensitive to Imipenem and Amikacin, but almost all were resistant to Ampicillin, Ceftriaxone and Co-trimoxazole, and variably sensitive to Amoxiclav, Gentamicin and Ciprofloxacin. Proteus species were $100 \%$ sensitve to Imipenem and $50 \%$ to Ceftriaxone and Amoxiclav, while $75 \%$ of them were resistant to Gentamicin and 50\% to Ciprofloxacin. (Tables IIIa and IIIb)

Pseudomonas species were found $100 \%$ sensitive to Imipenem and $75 \%$ to Amikacin, while $100 \%$ of the organism were resistant to Nitrofurantoin, $87.5 \%$ to Cotrimoxazole, $81 \%$ to Ceftriaxone, $68.8 \%$ to Ciprofloxacin and 
$68.75 \%$ to Gentamycin. (Tables IIIa and IIIb)

S. aureus were $100 \%$ sensitive to Vancomycin and $83 \%$ to Gentamycin and Amikacin each, while 100\% were resistant to Ampicillin but found variably sensitive to Amoxiclav (50\%), Oxacillin (50\%) and Ciprofloxacin (33\%). (Tables IIIa and IIIb)

Enterococci were found $83.3 \%$ sensitive to Imipenem, $66.7 \%$ to Ciprofloxacin and $50 \%$ were sensitive to Vancomycin, Gentamycin, Ceftriaxone, Co-trimoxazole and Amikacin all. Coagulase-negative Staphylococcus was $80 \%$ sensitive to Vancomycin and Imipenem each, while $80 \%$ were resistant to Ceftriaxone and Gentamicin each. (Tables IIIa and IIIb)

Table IIIa: Antibiotic sensitivity pattern of bacterial isolates

\begin{tabular}{|c|c|c|c|c|c|c|c|}
\hline \multirow[t]{2}{*}{ Isolated bacteria } & \multicolumn{2}{|c|}{ Sensitivity } & \multicolumn{5}{|c|}{ Number (\%) of isolates against antimicrobial agents } \\
\hline & pattern & AMP & $\mathrm{AMC}$ & OX & VAN & $\mathrm{CN}$ & CRO \\
\hline E. coli & $\mathrm{S}$ & $14(21.2)$ & $40(60.6)$ & $\mathrm{N} / \mathrm{D}$ & $\mathrm{N} / \mathrm{D}$ & $33(50.0)$ & $14(21.2)$ \\
\hline \multirow[t]{2}{*}{$(n=66)$} & IS & $00(00)$ & $26(39.4)$ & & & $00(00)$ & $04(06.1)$ \\
\hline & $\mathrm{R}$ & $52(78.8)$ & $00(00)$ & & & $33(50.0)$ & $48(72.7)$ \\
\hline Klebsiella & $\mathrm{S}$ & $00(00)$ & $36(60.0)$ & $\mathrm{N} / \mathrm{D}$ & $\mathrm{N} / \mathrm{D}$ & $12(20.0)$ & $09(15.0)$ \\
\hline \multirow[t]{2}{*}{$\operatorname{spp}(\mathrm{n}=60)$} & IS & $00(00)$ & $00(00)$ & & & $03(05.0)$ & $06(10.0)$ \\
\hline & $\mathrm{R}$ & $60(100)$ & $24(40.0)$ & & & $45(75.0)$ & $45(75.0)$ \\
\hline Proteus spp & $\mathrm{S}$ & $\mathrm{N} / \mathrm{D}$ & $08(50.0)$ & $\mathrm{N} / \mathrm{D}$ & $\mathrm{N} / \mathrm{D}$ & $04(25.0)$ & $08(50.0)$ \\
\hline \multirow[t]{2}{*}{$(n=16)$} & IS & & $03(18.75)$ & & & $00(00)$ & $03(18.75)$ \\
\hline & $\mathrm{R}$ & & $05(31.25)$ & & & $12(75.0)$ & $05(31.25)$ \\
\hline Pseudomonas & S & $\mathrm{N} / \mathrm{D}$ & $04(25.0)$ & $\mathrm{N} / \mathrm{D}$ & $\mathrm{N} / \mathrm{D}$ & $05(31.25)$ & $02(12.5)$ \\
\hline \multirow[t]{2}{*}{$\operatorname{spp}(\mathrm{n}=16)$} & IS & & $00(00)$ & & & $00(00)$ & $01(06.25)$ \\
\hline & $\mathrm{R}$ & & $12(75.0)$ & & & $11(68.75)$ & $13(81.25)$ \\
\hline Staphylococcus & $\mathrm{S}$ & 00 & $03(50.0)$ & $03(50.0)$ & $06(100)$ & $05(83.3)$ & $02(33.3)$ \\
\hline \multirow[t]{2}{*}{ aureus $(\mathrm{n}=06)$} & IS & 00 & $01(16.7)$ & $00(00)$ & $00(00)$ & $00(00)$ & $01(16.7)$ \\
\hline & $\mathrm{R}$ & $06(100)$ & $02(33.3)$ & $03(50.0)$ & $00(00)$ & $01(16.7)$ & $03(50.0)$ \\
\hline Enterococcus & S & $\mathrm{N} / \mathrm{D}$ & $\mathrm{N} / \mathrm{D}$ & $00(00)$ & $03(50.0)$ & $03(50.0)$ & $03(50.0)$ \\
\hline \multirow[t]{2}{*}{$\operatorname{spp}(n=6)$} & IS & & & $00(00)$ & $00(00)$ & $00(00)$ & $00(00)$ \\
\hline & $\mathrm{R}$ & & & $06(100)$ & $03(50.0)$ & $03(50.0)$ & $03(50.0)$ \\
\hline Coagulase-negative & $\mathrm{S}$ & $\mathrm{N} / \mathrm{D}$ & $03(60.0)$ & $01(20.0)$ & $04(80.0)$ & $01(20.0)$ & $01(20.0)$ \\
\hline Staphylococcus & IS & & $00(00)$ & $00(00)$ & $00(00)$ & $00(00)$ & $00(00)$ \\
\hline$(n=5)$ & $\mathrm{R}$ & & $02(40.0)$ & $04(80.0)$ & $01(20.0)$ & $04(80.0)$ & $04(80.0)$ \\
\hline
\end{tabular}

$\mathrm{S}=$ Sensitive, $\mathrm{IS}=$ Intermediately Sensitive, $\mathrm{R}=$ Resistant

$\mathrm{AMP}=$ Ampicillin, $\mathrm{AMC}=$ Amoxiclav, $\mathrm{OX}=$ Oxacillin, $\mathrm{VAN}=$ Vancomycin, $\mathrm{CN}=$

Gentamycin, $\mathrm{CRO}=$ Ceftriaxone
Table IIIb: Antibiotic sensitivity pattern of bacterial isolates

\begin{tabular}{|c|c|c|c|c|c|c|c|}
\hline \multirow[t]{2}{*}{ Isolated bacteria } & \multicolumn{2}{|c|}{ Sensitivity } & \multicolumn{5}{|c|}{ Number (\%) of isolates against antimicrobial agents } \\
\hline & pattern & CIP & $\mathrm{F}$ & $\mathrm{CAZ}$ & SXT & IMP & AK \\
\hline E. coli & S & $23(34.9)$ & $56(84.9)$ & $20(33.3)$ & $10(15.2)$ & $53(80.3)$ & $53(80.3)$ \\
\hline \multirow[t]{2}{*}{$(\mathrm{n}=66)$} & IS & $00(00)$ & $00(00)$ & $14(21.2)$ & $03(04.5)$ & $13(19.7)$ & $03(04.5)$ \\
\hline & $\mathrm{R}$ & $43(65.2)$ & $10(15.1)$ & $32(48.5)$ & $53(80.3)$ & $00(00)$ & $10(15.2)$ \\
\hline Klebsiella & $\mathrm{S}$ & $18(30.0)$ & $40(66.7)$ & $15(25.0)$ & $06(10.0)$ & $60(100.0)$ & $51(85.0)$ \\
\hline \multirow[t]{2}{*}{$\operatorname{spp}(\mathrm{n}=60)$} & IS & $03(05.0)$ & $02(03.3)$ & $00(00)$ & $00(00)$ & $00(00)$ & $02(03.3)$ \\
\hline & $\mathrm{R}$ & $39(65.0)$ & $18(30.0)$ & $45(75.0)$ & $54(90.0)$ & $00(00)$ & $07(11.7)$ \\
\hline Proteus spp & S & $06(37.5)$ & $08(50.0)$ & $02(12.5)$ & $05(31.3)$ & $16(100.0)$ & $08(50.0)$ \\
\hline \multirow[t]{2}{*}{$(\mathrm{n}=16)$} & IS & $02(12.5)$ & $00(00)$ & $00(00)$ & $03(18.7)$ & $00(00)$ & $00(00)$ \\
\hline & $\mathrm{R}$ & $08(50.0)$ & $08(50.0)$ & $14(87.5)$ & $08(50.0)$ & $00(00)$ & $08(50.0)$ \\
\hline Pseudomonas & S & (18.7) & $00(00)$ & $08(50.0)$ & $00(00)$ & $16(100.0)$ & $12(75.0)$ \\
\hline \multirow[t]{2}{*}{$\operatorname{spp}(\mathrm{n}=16)$} & IS & $02(12.5)$ & $00(00)$ & $00(00)$ & $02(12.5)$ & $00(00)$ & $00(00)$ \\
\hline & $\mathrm{R}$ & $0311(68.8)$ & $16(100.0)$ & $08(50.0)$ & $14(87.5)$ & $00(00)$ & $04(25.0)$ \\
\hline Staphylococcus & S & $02(33.3)$ & $\mathrm{N} / \mathrm{D}$ & $\mathrm{N} / \mathrm{D}$ & $\mathrm{N} / \mathrm{D}$ & $\mathrm{N} / \mathrm{D}$ & $05(83.3)$ \\
\hline \multirow[t]{2}{*}{ aureus $(\mathrm{n}=06)$} & IS & $01(16.7)$ & & & & & $01(16.7)$ \\
\hline & $\mathrm{R}$ & $03(50.0)$ & & & & & $00(00)$ \\
\hline Enterococcus & S & $04(66.7)$ & $\mathrm{N} / \mathrm{D}$ & $\mathrm{N} / \mathrm{D}$ & $03(50.0)$ & $05(83.3)$ & $03(50.0)$ \\
\hline \multirow[t]{2}{*}{$\operatorname{spp}(\mathrm{n}=6)$} & IS & $00(00)$ & & & $00(00)$ & $00(00)$ & $00(00)$ \\
\hline & $\mathrm{R}$ & $02(33.3)$ & & & $03(50.0)$ & $01(16.7)$ & $03(50.0)$ \\
\hline Coagulase-negative & S & $01(20.0)$ & $\mathrm{N} / \mathrm{D}$ & $\mathrm{N} / \mathrm{D}$ & $02(40.00)$ & $04(80.0)$ & $03(60.0)$ \\
\hline Staphylococcus & IS & $00(00)$ & & & $01(20.00)$ & $01(20.0)$ & $00(00)$ \\
\hline$(\mathrm{n}=5)$ & $\mathrm{R}$ & $04(80.0)$ & & & $02(40.00)$ & $00(00)$ & $02(40.0)$ \\
\hline
\end{tabular}

\section{Discussion}

Identification of the uropathogens and their susceptibility pattern is very important in treating the cases of Urinary Tract Infections (UTI). In the present study, urine specimens were cultured to see pattern of uropathogens and some 175 (48.61\%) of the urine showed significant growth of bacteria. So, majority $(51.38 \%)$ of the cases remaining showed either insignificant bacteriuria or no growth with urine from the suspected cases of UTI. Prior antibiotic therapy before submitting the urine samples, and clinical conditions like non-gonococcal urethritis or others that mimic UTI could be the factors responsible for insignificant bacteriuria or no growth. Furthermore, $2.86 \%$ of the urine samples showing growth of Coagulase-negative Staphylococcus which are supposed to be non-pathogenic. This indicates the need for educating the patients about the method of collection of clean catch mid-stream urine specimens. 
The age and sex distribution of the patients diagnosed with UTI among the hospitalized patients and those attending the outpatient department followed the natural epidemiological pattern of UTI. There were a higher number of young male children. Similarly, there was a predominance of young and middle aged females, whereas in the older age groups of more that 60 years, equal proportions of male and females had UTI.

In the present study, the Enterobacteriaceae group were the most common pathogens isolated (Escherichia coli-37.71\%, Klebsiella species-34.29\%, and Proteus species-9.71\%), followed by Pseudomonas (9.14\%), Staphylococcus aureus $(3.43 \%)$, Enterococci $(2.86 \%)$ and Coagulase-negative Staphylococcus $(2.86 \%)$. The isolation rate of urinary pathogens of the present study is consistent with reports of the studies published elsewhere recently. $9,15,16$

Isolation rate of $S$. aureus, which causes UTI rarely, was $3.43 \%$ in the present study. There were a few patients with either renal calculus or hydronephrosis (not shown in the result) who could have prior catheterization or may even be suffering from bacteremic kidney infections. Hence, this could probably explain the current isolation rate of $S$. aureus from the cases of nosocomial UTI in the study.

E. coli was the principal pathogen isolated showing a high susceptibility to Nitrofurantoin (85\%), Imipenem (80\%) and Amikacin (80\%), but showed variable sensitivity to other commonly used antibiotics. This is consistent with reports from different countries who have reported an increasing resistance to Ampicillin, Ciprofloxacin, and Ceftriaxone.9,16,17 Another study from Bangladesh reported an increased resistance of the uropathogens to Ciprofloxacin. ${ }^{10}$

In the present study, Klebsiella species showed high susceptibility to Imipenem (100\%) and Amikacin (85\%) but were relatively resistant to commonly used antibiotics. Proteus species were $100 \%$ susceptible to Imipenem, 50\% to Amikacin, Nitrofurantoin, Ceftriaxone and Amoxiclav each. This finding is comparable to Manjula et al of India, ${ }^{18}$ who found members of Enterobacteiacae variably sensitive to Amoxiclav, Ceftriaxone, Ceftazidime and Ciprofloxacin but found all isolates sensitive to Imipenem. Similar susceptibility pattern were also reported by other investigators. ${ }^{19}$

Pseudomonas species, a common cause of hospital-acquired UTI, was found less sensitive to the common antibiotics but sensitive to Imipenem (100\%) and Amikacin (75\%). Similar results were reported by investigators from other countries. ${ }^{16,20}$ Pseudomonas species were relatively susceptible to the second line of anti-pseudomonas drugs and most of these were associated with high-level resistance to the first-line antibiotics investigated namely Amoxiclav, Ceftriaxone, Ciprofloxacin and Gentamicin. This may be due to widespread use of common antibiotics in the hospital and cross-resistance among different bacteria.

S. aureus were found $100 \%$ sensitive to Vancomycin, $83 \%$ to Amikacin and Gentamicin each but were less susceptible to other common antibiotics. Coagulase-negative Staphylococcus were $80 \%$ sensitive to Vancomycin and Imipenem but relatively resistant to other antibiotics. Similar to the present study, a recent report from Bangladesh Institute of Research in Diabetes, Endocrine and Metabolic disorders (BIRDEM), Dhaka had shown that S. aureus was $100 \%$ sensitive to Vancomycin and mostly resistant to Ampicillin. ${ }^{21}$ Almost similar susceptibility pattern was also reported by other investigators. ${ }^{16}$

As regards to Enterococci, $83 \%$ of the isolates were sensitive to Imipenem, $67 \%$ to Ciprofloxacin, $50 \%$ to each of Vancomycin, Gentamicin and Ceftriaxone. A report from the SENTRY Antimicrobial Surveillance Program, USA also has shown similar results. ${ }^{16}$

The results of the present study showed that sensitivity rate of the uropathogens were low for Co-trimoxazole and Ampicillin. This low sensitivity could be due to widespread use of the antibiotics in the community. It is possible that the low sensitivity is present among uropathogens of the nosocomial as well as community-acquired UTI. The patients attending outpatient department and some of the hospitalized patients may be having community-acquired UTI. In the present study, community-acquired UTI and nosocomial UTI were not been distinguished. This was the main limitation of the study.

A high isolation rate of pathogens from urine samples of clinically suspected UTI shows a good correlation between clinical findings and microbiological methods. Gram-negative bacteria were the commonest organisms isolated, among which E. coli was the principal urinary pathogen. Data presented in this study indicate that antibiotics commonly used for the treatment of nosocomial UTIs are less effective. Since this was a cross-sectional study, further regular monitoring is required to establish reliable information about 
susceptibility pattern of urinary pathogens for optimal therapy of patients with nosocomial UTI.

\section{References}

1. Ronald AR, Puttulo MS. The natural history of urinary infection in adults. Med Clin North Am 1991; 75: 299-312.

2. Liperky BA. Urinary tract infection in men: epidemiology, patholophysiology, diagnosis and treatment. Ann Intern Med 1989; 111: 138-150.

3. New CH. Urinary tract infection. Am J Med 1992; 4A (supp 1): 63-70.

4. Gebre-Selassie S. Asymptomatic bacteriuria in pregnancy: epidemiological, clinical and microbiological approach. Ethiop Med J 1998; 36: 185-192.

5. Pastore LM, Savitz DA, Thorp JM. Predictors of symptomatic Urinary tract infection after 20 weeks gestation. J Perinatol 1999; 19: 488-493.

6. Tambiah PA, Maki DG. Catheter associated UTI is rarely symptomatic; a prospective study of 1497 catheterized patients. Arch Int Med 2000; 160: 678-682.

7. Van Nostrand JD, Junkins AD, Bartholdi RK. Poor predictive ability of urinanalysis and microscopic examination to detect urinary tract infection. Am J Clin Pathol 2000; 113: 709-713.

8. Srinivassa H, Parija SC, Bhattacharya S, Sehgal R. Incidence of ciprofloxacin resistance in urinary isolates. Eastern Nepal $\mathrm{J}$ Comm Dis 1999; 31: 45-47.

9. Navaneeth BV, Belwadi S, Suganthi N. Urinary pathogens, resistance to common antibiotics: a retrospective analysis. Trop Doct 2002; 32: 20.

10. Iqbal J, Rahman M, Kabir MS, Rahman M. Increasing ciprofloxacin resistance among prevalent urinary tract bacterial isolates in Bangladesh. Jpn J Med Sci Biol 1997; 50: 241-250.

11. Sleigh JD, Duguid JP. Salmonella. In: Collee JG, Duguid JP, Fraser AG, Marmion BP, eds. Mackie \& McCartney Practical Medical Microbiology, Vol 2, 13th ed. New York: Churchill Livingstone; 1989: pp. 456-481.
12. Cruickshank R, Duguid JP, Marmion BP. Tests for identification of bacteria. In: Medical Microbiology, Vol 2, 12th ELBS ed. London: Churchill Livingstone; 1975: pp. 170-189.

13. Bauer AW, Kirby WMM, Sherris JC, Turch M. Antibiotic susceptibility testing by a standardized single disk method. Am J Clin Pathol 1966; 45: 493-499.

14. National Committee for Clinical Laboratory Standards. Approved standard M2A7: Performance standards for antimicrobial susceptibility testing. Eighth informational supplement. Villanova, PA: NCCLS; 2000.

15. Abu Shaqra Q. Occurrence and antibiotic sensitivity of Enterobacteriaceae isolated from a group of Jordanian patients with community acquired urinary tract infections. Cytobios 2000; 101: 15-21.

16. Jones RN, Kugler KC, Pfaller MA, Winokur PL. Characteristics of pathogens causing urinary tract infections in hospitals in north America. Results from the SENTRY Antimicrobial Surveillance Program, 1997. Diagn Microbiol Infect Dis 1999; 35: 55-63.

17. Allen UD, MacDonald N, Fuite L, Chan F, Stephens D. Risk factors for resistance to first line antibiotics among urinary trsct isolates of Escherichia coli in children. CMAJ 1999; 160: 436476.

18. Manjula M, Priya D, Varsha G. Detection of extended spectrum beta lactamase producers among surgical wound infections and burn patients in JIPMER. Indian J Med Microbiol 2006; 18: 160-165.

19. Rossi A, Tokumoto M, Galas M, Sooaga R, Corso A. Monitoring antibiotic resistance in Argentina. The WHONET program, 1995-96. Rev Panam Sulud Publica 1999; 6: 234-41. [Spanish]

20. Kahlmeter G, ECO. SENS. An international survey of the antimicrobial susceptibility of pathogens from uncomplicated urinary tract infections: the ECO. SENS Project. J Antimicrob Chemother, 2003; 51: 69-76.

21. Huq JA. Prevalence of antibiotic resistance in medically important bacteria in Bangladesh and their molecular characterization. A multicentre study, BMRC project report. 2002; pp. 47-50. 